\title{
FEM SIMULATION OF STRAIN DISTRIBUTION THROUGH THICKNESS OF MULTILAYERED METAL COMPOSITE PROCESSED BY ASYMMETRIC ACCUMULATIVE ROLL BONDING
}

\author{
Natalya LOKOTUNINA, Alexander PESIN, Denis PUSTOVOYTOV, Dmitry GRACHEV
}

Nosov Magnitogorsk State Technical University, Magnitogorsk, Russian Federation, $\underline{\text { nml76@mail.ru }}$

https://doi.org/10.37904/metal.2019.703

\begin{abstract}
Accumulative roll bonding (ARB) is one of the severe plastic deformation methods of producing ultrafine grained laminated metal composites (LMCs). In order to obtain one-body solid material, the rolling in ARB is not only a deformation process but also a roll-bonding process. ARB technique can be applied to generate LMCs consisting of layers of the same one material or several dissimilar materials. This paper is focused on LMCs consisting of dissimilar metal system of aluminum alloys 1050/6061 and 1050/6061/1050. One difficulty of roll bonding dissimilar materials is obtaining of elevated strain at the interface of the composite in order to provide the ultrafine grain structure and superior bonding strength between the stacked layers. Compared to conventional ARB the asymmetric accumulative roll bonding is more appropriate for the production of dissimilar metal composites. This paper presents the results of the finite element simulation and comparison of interface strain behavior during conventional and asymmetric ARB of 1050/6061 and 1050/6061/1050 Al composites. Influence of rolls speed ratio and contact friction on strain distribution through composite thickness, especially on interface between the 1050 and 6061 layers, during asymmetric ARB were analyzed by FEM in details. The FEM results of investigation can be useful for the development of the improved ARB process of Al composites with UFG structure and high bond strength.
\end{abstract}

Keywords: Metal composite, asymmetric accumulative roll bonding, finite element method, strain, interface

\section{INTRODUCTION}

Large-scaled sheets with laminated structures, which are denoted as laminated metal composites (LMCs), can be produced by accumulative roll bonding (ARB) process [1]. In order to obtain one body solid material, the rolling in ARB is not only a deformation process but also a roll-bonding process. ARB technique can be applied to generate LMCs consisting of layers of the same one material or several dissimilar materials. Aluminum alloys are particularly suitable for the ARB process due to its high light-weight potential and good cold rollbonding capability. Lately, more and more studies have been focused on UFG LMCs consisting of bimetal systems fabricated by ARB, such as AA6014/AA5754 [2], AA1050/AA6061 [3], AA1100/AA7075 [4], AA5005/AA6061 [5], AA2219/AA5086 [6]. Compared to conventional ARB the asymmetric accumulative roll bonding can be more appropriate for the production of dissimilar bimetal composites. The difficulty of roll bonding dissimilar materials is necking and finally rupturing of the harder layer with increasing ARB cycles caused by the difference in plastic flow behavior. The main disadvantage of ARB process is a low productivity because of a lot of cycles needed for achieving of certain amount of strain and high bond strength. Since accumulative or effective strain " $e$ " plays a key role in grain misorientation, an increase of $e$ may accelerate the evolution toward an ultrafine microstructure subdivided by high angle boundaries (HABs). In other words, if a certain amount of strain is required for the formation of ultrafine grains surrounded by HABs, an increase in e might result in a decrease in the number of passes and hence in a higher productivity of ARB process. Moreover, the grain refining effectiveness of the ARB process would be higher with increasing e. Finally, increasing $e$ leads to a superior bonding strength between the stacked layers. In order to obtain a higher accumulated strain, the ARB process should have an additive shear component. A small amount of shear strain is observed for conventionally rolled materials because of contact friction between sheet and rolls. However, during conventional ARB, shear strain is restricted only to the near surface region. Moreover, during 
conventional ARB the contact friction should be kept at a low level in order to prevent excessive rolling force. Elevated shear strain can be introduced into the material by asymmetric rolling in which the speeds of the top and bottom rolls are different [7-9]. Yu et al. [10] studied the bonding strength of ultrathin UFG bimetal foils produced using ARB followed by asymmetric rolling. The interface bonding strength was found to increase as the number of rolling passes increased. TEM inspection showed that the interface quality was the best when the roll speed ratio was 1.2. There were no noticeable residual voids at the interface of the AA1050/AA6061 bimetallic foils for this roll speed ratio; however, residual voids were observed when the roll speed ratio was 1.0 or 1.4. As shown by the literature review some experimental investigations on the microstructural and mechanical properties evolution of bimetal system of aluminum alloys processed by asymmetric ARB have been already done. However, the explanations of mechanism of grain refinement at the interface of the composite and the formation of superior bonding strength between the stacked layers during asymmetric ARB has not been found. The goal of this paper is investigation of strain distribution through thickness of 1050/6061 and 1050/6061/1050 bimetal Al composites during asymmetric ARB and explanation of mechanism of formation of superior bonding strength between the stacked layers.

\section{RESEARCH METHOD}

Simulations of the ARB process was carried out using the commercial FEM code DEFORM 2D. Only numerical simulations were performed in this research. The geometry model and FE meshing of 1050/6061 and 1050/6061/1050 bimetal Al composites are shown in Figure 1. Bimetal composites with total thickness of 1.0 $\mathrm{mm}$ and $1.5 \mathrm{~mm}$ consisted of AA1050 and AA6061 layers (Figure 1). The stress-strain curves of the aluminum alloys 1050 and 6061 at room temperature are shown in Figure 2. Sticking boundary conditions, which prevented sliding or separation on interface between the AA1050 and AA6061 layers, were defined.

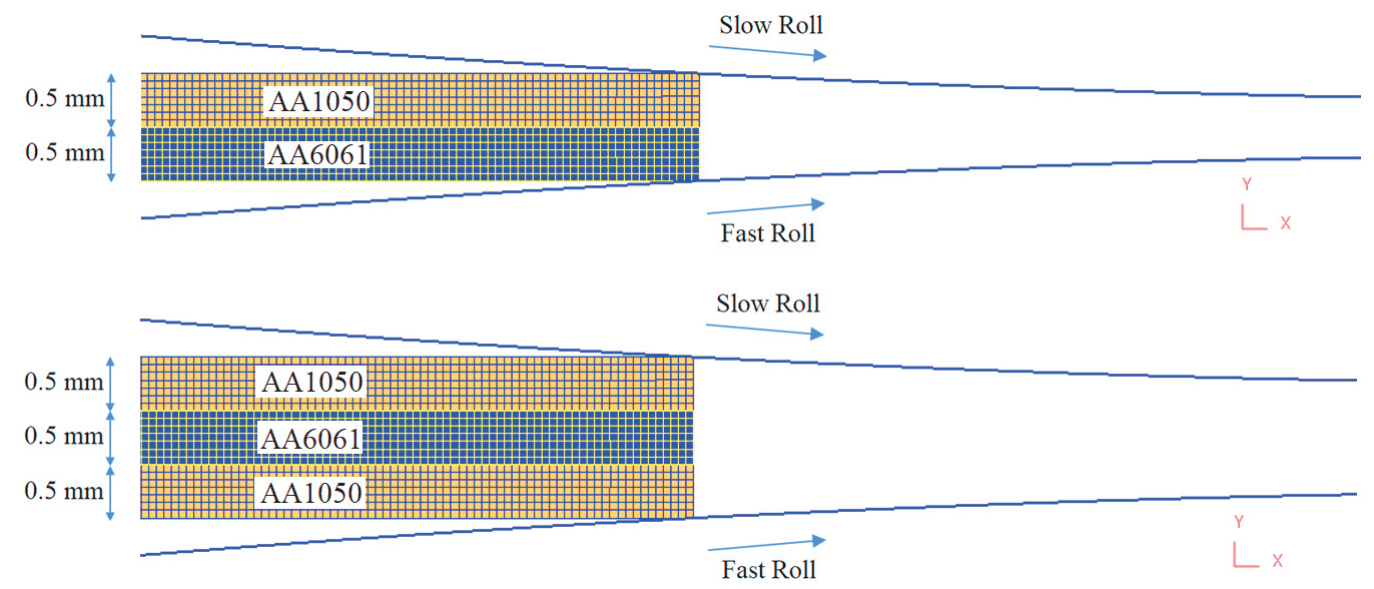

Figure 1 Geometry model and FE meshing of 1050/6061 and 1050/6061/1050 bimetal Al composites

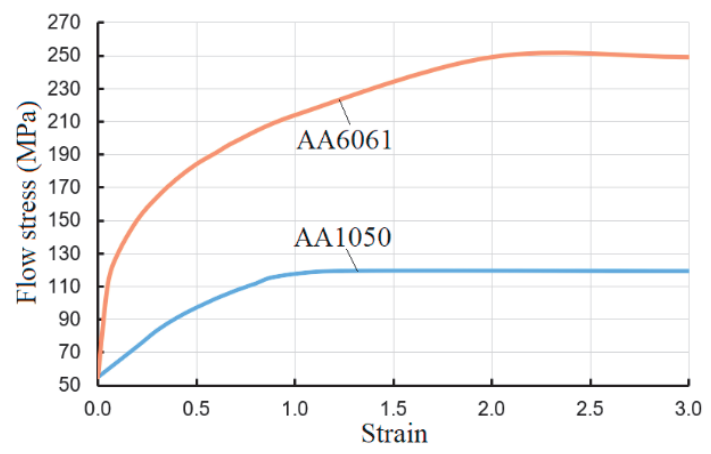

Figure 2 Stress-strain curves of aluminum alloys AA1050 and AA6061 at room temperature 
Asymmetric ARB process was performed by a single pass with a thickness reduction of $50 \%$. So, the final thicknesses of bimetal composites 1050/6061 and 1050/6061/1050 were $0.5 \mathrm{~mm}$ and $0.75 \mathrm{~mm}$, respectively. The modeling of the process was performed at room temperature without taking into account the increment of the metal's temperature due to the thermal effect of deformation and friction. The diameters of the rolls were $360 \mathrm{~mm}$, and the rolls were considered as rigid. The bottom roll was rotated at the higher speed $\left(10 \mathrm{~min}^{-1} \mathrm{in}\right.$ all calculation variants. Speed of the top roll in contact with the AA1050 layer was reduced by $5 \ldots 50 \%$ with the step of $5 \%$. A Coulomb friction model was used between rolls and strip. The number of brick elements was $4000 \ldots 10000$ for each layer of bimetal composite. An automatic remeshing was used. AA1100 and AA6061 were chosen as hardened rigid-plastic materials. Influence of rolls speed ratio $(0 \ldots 50 \%)$ and contact friction coefficient $(0.1 \ldots 0.3)$ on strain distribution through composite thickness, especially on interface between the AA1050 and AA6061 layers, during asymmetric ARB were analyzed by FEM in details.

\section{SIMULATION RESULTS AND DISCUSSION}

Measuring of the curve of bonding interface during conventional ARB with the friction coefficient of 0.1 has shown that it looks like wave with a small damped amplitude (Figure 3). The increasing friction coefficient from 0.1 to 0.3 leads to small increasing of amplitude, however, it does not exceed $+0.008 \ldots-0.006 \mathrm{~mm}$ in all cases (Figure 4). It should be noted that the lengths of the deformation zones in all cases are different. So, the enter planes and exit planes are not always the same. It can be explained by material bending depending on rolling conditions.

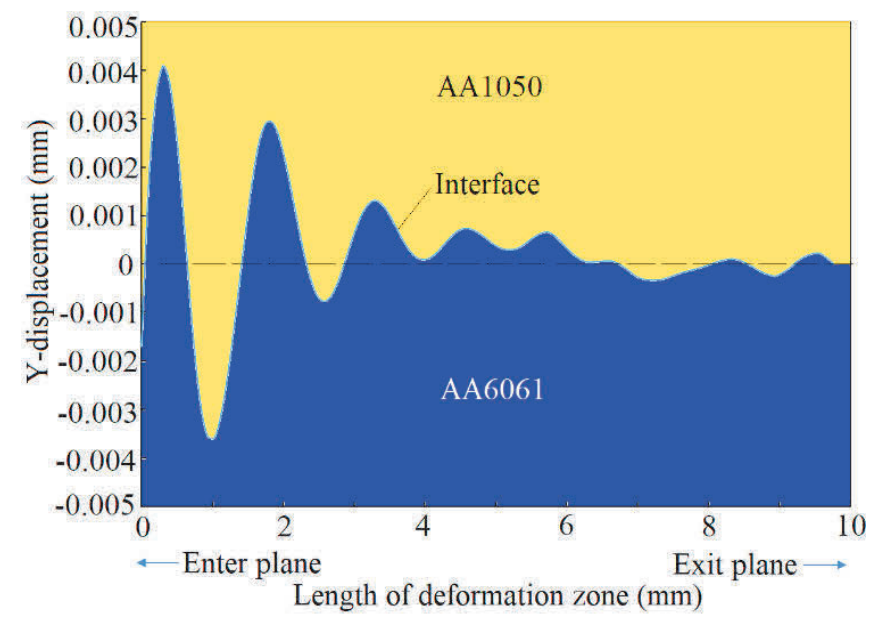

Figure 3 Calculated curve of interface in the deformation zone during conventional ARB of 1050/6061 Al composite (friction coefficient is 0.1)

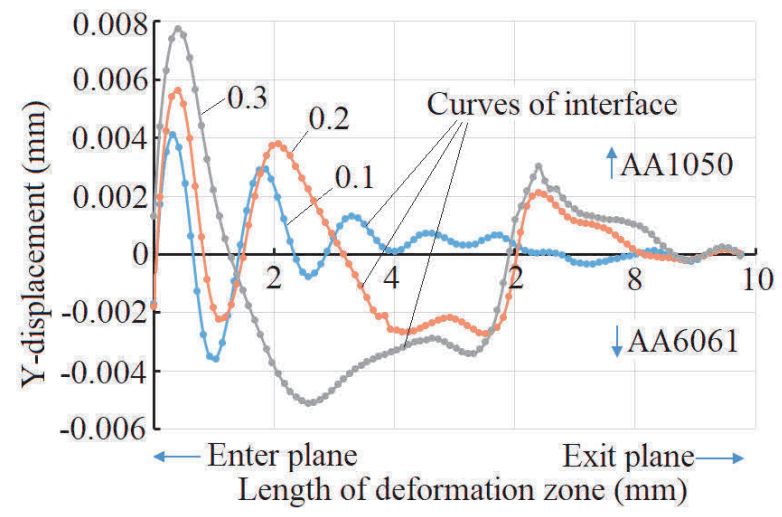

Figure 4 Influence of friction coefficient on curve of interface during conventional ARB of AA1050/AA6061 
The increasing friction coefficient from 0.1 to 0.3 leads to a very small increasing of the strain in the soft and in the hard layers of interface during conventional ARB. Strain in the soft layer (AA1050) was only increased from $e=0.83$ to $e=0.88$, and strain in the hard layer (AA6061) was increased from $e=0.81$ to $e=0.85$. Another situation occurs during asymmetric ARB with simultaneous increasing of the friction coefficient and the rolls speed ratio $\Delta V$. The inhomogeneous strain has occurred in each of the constituent metals based on the observation of bonding interface during asymmetric ARB with different rolls speed ratio. Measuring of the curve of bonding interface in the deformation zone has shown that the increasing the rolls speed ratio from $\Delta V$ $=0$ to $\Delta V=40 \%$ leads to increasing of amplitude up to 10 times: from $+0.008 \ldots-0.006 \mathrm{~mm}$ to $+0.01 \ldots-0.068 \mathrm{~mm}$ (Figure 5). However, after reaching the optimal value of rolls speed ratio $(\Delta V=40 \%)$ the amplitude is sharply decreased. In all cases the soft material is penetrated into the hard material (Figure 6). Thus, a very strong correlation between the amplitude of wave of bonding interface and the strain at the interface was found.

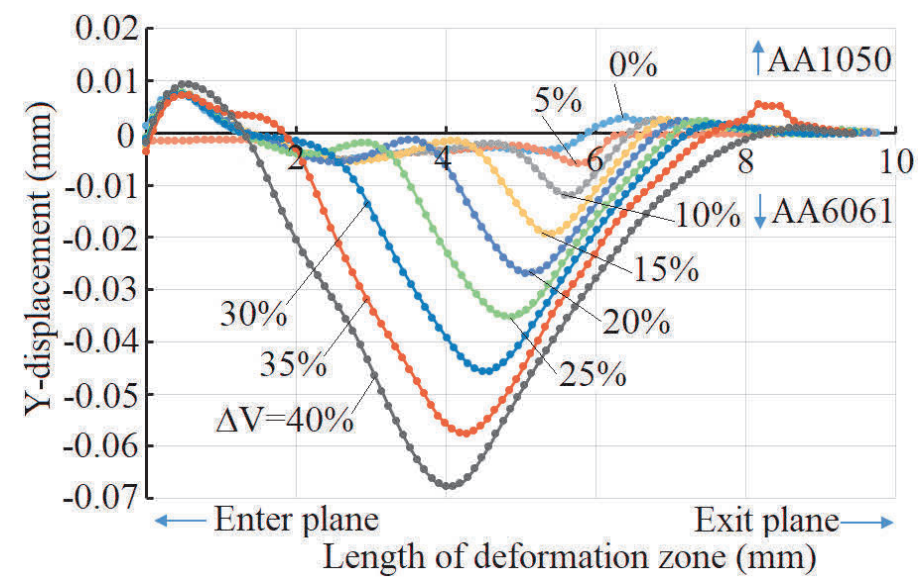

Figure 5 Calculated curve of interface during asymmetric ARB AA1050/AA6061 with high contact friction 0.3

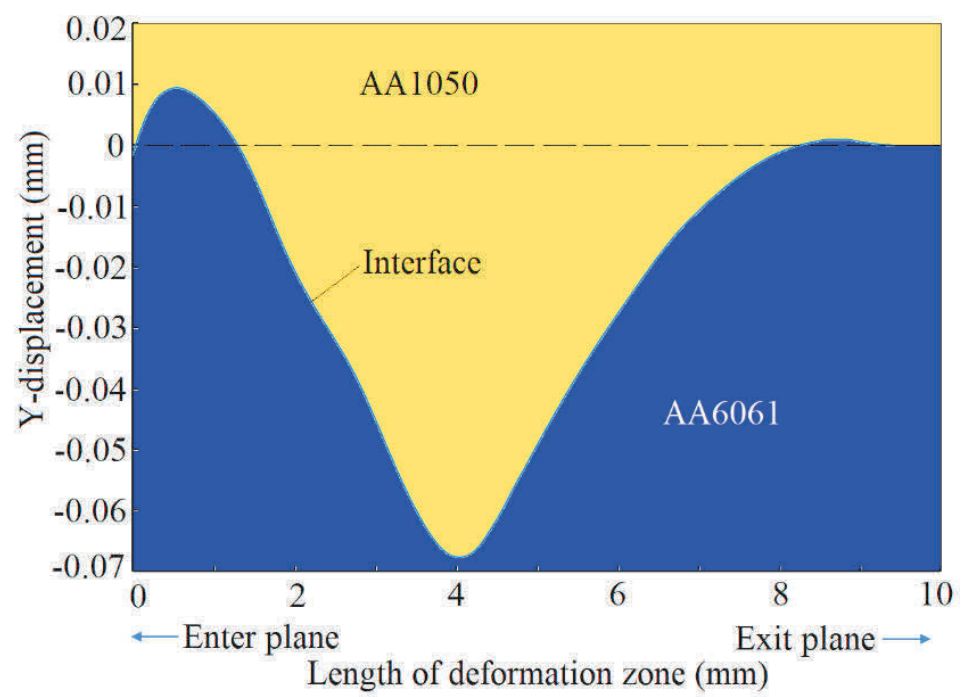

Figure 6 Calculated curve of interface in the deformation zone during asymmetric ARB of $1050 / 6061 \mathrm{Al}$ composite with high contact friction 0.3 and optimal rolls speed ratio $\Delta V=40 \%$

At low friction coefficient, e.g. $f=0.1 \ldots 0.2$, there is not a serious effect of the rolls speed ratio on strain at the interface. A very high amount of strain at the interface can be observed during asymmetric ARB only with combination of optimal $\Delta V$ and high friction, e.g. $f=0.3 \ldots 0.4$. The results of the numerical simulations have 
demonstrated that the right combination of friction coefficient and the optimal ratio of work rolls speeds lead to a very high strain at the interface.

Strain fields in the Al bimetal composites during different strategies of ARB are shown in Figure 7. Strain is low and quite uniform through all thickness during conventional ARB with high contact friction of 0.3 (Figure 7a). Almost the same situation we have during asymmetric ARB with high $\Delta V=40 \%$ and low contact friction of 0.1 (Figure 7b). Strain distribution through thickness of the asymmetrically rolled 1050/6061 Al bimetal composite becomes very nonuniform when $\Delta V$ is optimal and contact friction is high (Figure 7c). Very high strain up to $e=8$ is localized at the interface in the soft layer of AA1050 during asymmetric ARB with optimal $\Delta V=40 \%$ and high friction of 0.3 . Thereby the strain at the interface is increased approximately up to 10 times: from $e=0.82 \ldots 0.88$ to $e=8$ (Figure 7c). It can be explained by the amplitude of curve of bonding interface. Increasing of strain is strongly correlated to increasing of amplitude of interface curve, which also is increased approximately up to 10 times (Figure 6). Thus, elevated shear strain can be introduced at the interface of the composite 1050/6061 by asymmetric ARB with optimal rolls speed ratio and high contact friction. Since the strain at the interface can be seriously increased, then the ultrafine grain size and the superior bonding strength between the stacked layers are expected during one cycle of asymmetric ARB. However, this is only possible for ARB processing of soft-hard double-layer Al composites such as 1050/6061. Because the asymmetric ARB does not have serious influence on the strain at the interfaces of three-layer Al composites of the type soft-hard-soft, such as, for example, 1050/6061/1050 (Figure 7d).

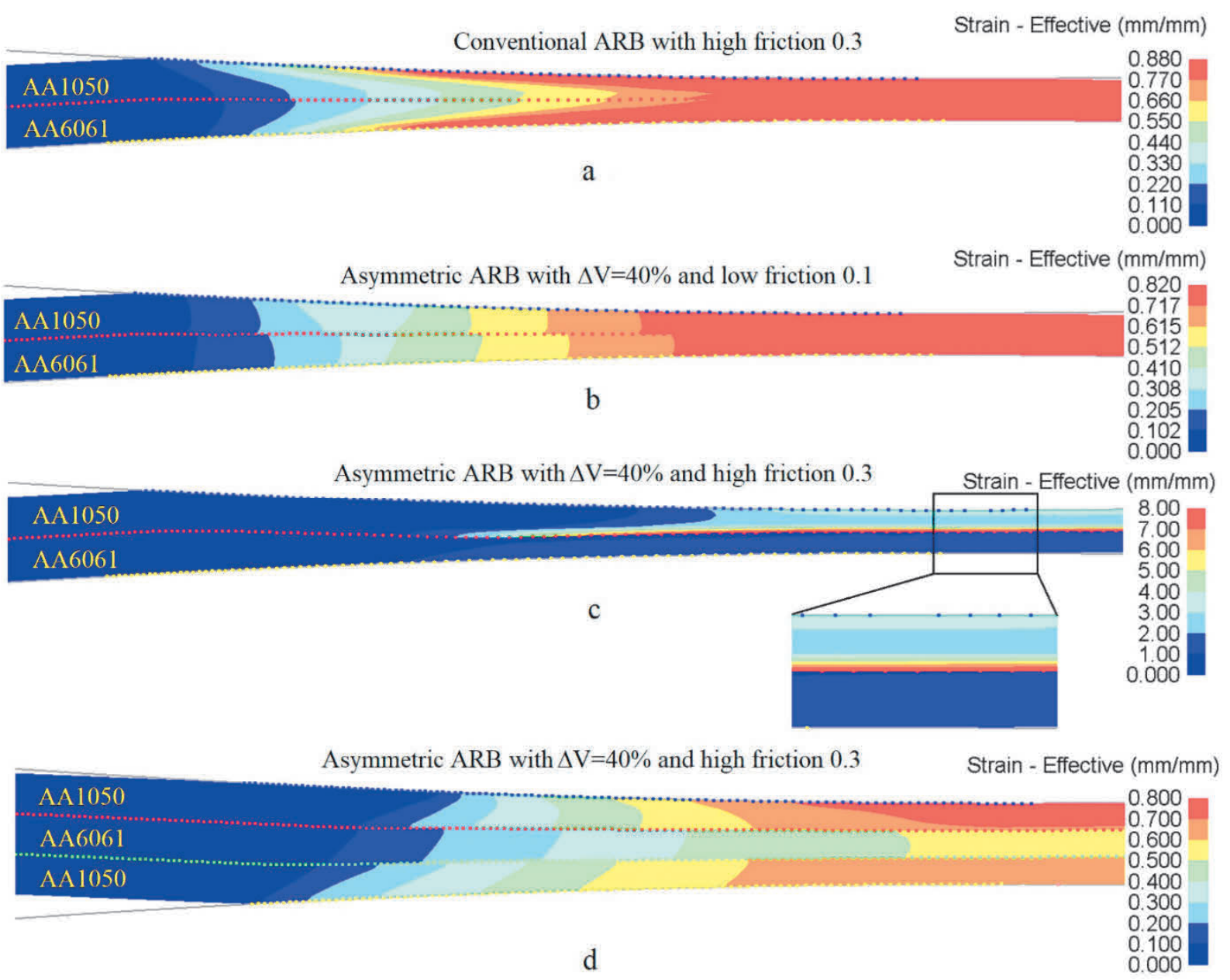

Figure 7 Fields of strain effective in the 1050/6061 (a, b, c) and 1050/6061/1050 (d) Al composites during different strategies of ARB: a - conventional ARB with the high friction of $0.3 ; b$ - asymmetric ARB with the $\Delta V=40 \%$ and low friction of $0.1 ; \mathrm{c}, \mathrm{d}$ - asymmetric ARB with the optimal $\Delta V=40 \%$ and high friction of 0.3 


\section{CONCLUSION}

Elevated shear strain can be introduced at the interface of the Al composite 1050/6061 by asymmetric ARB with optimal ratio of work rolls speeds and high contact friction. Asymmetric ARB corresponds to the process in which the speeds of the top and bottom rolls are different. It was numerically shown that for Al composite $1050 / 6061$ the strain in soft layer (AA1050) of the interface can be extremely increased up to $e \approx 8$ while the strain in hard layer (AA6061) is about $e \approx 1$. The mechanism of strain increasing is to increase the amplitude of interface curve. Increasing of strain is strongly correlated to increasing of amplitude of interface curve. Since the strain at the interface can be seriously increased, then the ultrafine grain size and the superior bonding strength between the stacked layers are expected during one cycle of asymmetric ARB. However, asymmetric ARB does not have serious influence on the strain at the interfaces of three-layer Al composites of the type soft-hard-soft, such as, for example, 1050/6061/1050. The FEM results can be useful for the development of the improved ARB process of Al composites with UFG structure and high bond strength. A validation of the numerical results with experimental tests is required.

\section{ACKNOWLEDGEMENTS}

\section{The study was supported by a grant of the Russian Science Foundation (contract No 15-19-10030).}

\section{REFERENCES}

[1] LESUER, D.R., SYN, C.K., SHERBY, O.D., WADSWORTH, J., LEWANDOWSKI, J.J. and HUNT, W.H. Mechanical behavior of laminated metal composites. International Materials Reviews. 1996. vol. 41, pp. 169-197.

[2] HAUSÖL, T., HÖPPEL, H.W. and GÖKEN, M. Microstructure and Mechanical Properties of Accumulative Roll Bonded AA6014/AA5754 Aluminium Laminates. Materials Science Forum. 2011. vols. 667-669, pp. $217-222$.

[3] SU, L.H., LU, C., DENG, G.Y., TIEU, K. and SUN, X.D. Microstructure and mechanical properties of 1050/6061 laminated composite processed by accumulative roll bonding. Reviews on Advanced Materials Science. 2013. vol. 33, pp. 33-37.

[4] CHEN, Z. and CHEN, Q. Interface Shear Actions and Mechanical Properties of Nanostructured Dissimilar Al Alloy Laminated Metal Composites. Journal of Nanomaterials. 2015. vol. 2015. Article ID 612029.

[5] SU, L., LU, C., DENG, G. and TIEU, K. Microstructure and mechanical properties of AA5005/AA6061 laminated composite processed by accumulative roll bonding. Metallurgical and Materials Transactions B: Process Metallurgy and Materials Processing Science. 2014. vol. 45, pp. 515-522.

[6] ROY, S., NATARAJ, B.R., SUWAS, S., KUMAR, S. and CHATTOPADHYAY, K. Microstructure and texture evolution during accumulative roll bonding of aluminium alloys AA2219/AA5086 composite laminates. Journal of Materials Science. 2012. vol. 47, pp. 6402-6419.

[7] YU, H., TIEU, K. and LU, C. Advanced rolling technologies for producing ultrafine-grain/nanostructured alloys. Procedia Engineering. 2014. vol. 81, pp. 96-101.

[8] PESIN, A. and PUSTOVOYTOV, D. Finite element simulation of extremely high shear strain during a single-pass asymmetric warm rolling of Al-6.2Mg-0.7Mn alloy sheets. Procedia Engineering. 2017. vol. 207, pp. 1463-1468.

[9] PESIN, A. and PUSTOVOYTOV, D. Influence of process parameters on distribution of shear strain through sheet thickness in asymmetric rolling. Key Engineering Materials. 2014. vols. 622-623, pp. 929-935.

[10] YU, H., TIEU, A.K., LU, C. and GODBOLE, A. An Investigation of Interface Bonding of Bimetallic Foils by Combined Accumulative Roll Bonding and Asymmetric Rolling Techniques. Metallurgical and Materials Transactions A. 2014. vol. 45, pp. 4038-4045. 